\title{
Malignant Skin Neoplasms
}

\author{
Carlos Ricotti, MD ${ }^{a}$, Navid Bouzari, MD ${ }^{\mathrm{b}}$, AmarAgadi, MD ${ }^{\mathrm{c}}$, \\ Clay J. Cockerell, $\mathrm{MD}^{\mathrm{a}, \mathrm{c}, *}$
}

\section{KEYWORDS \\ - Skin cancer • Basal cell carcinoma • Melanoma \\ - Squamous cell carcinoma • Skin neoplasms}

Skin cancer is the most common form of cancer in the United States, with the incidence increasing considerably. At current rates in the United States, a skin cancer will develop in 1 in 6 people during their lifetime. ${ }^{1}$ The most common of skin cancers may be categorized into 2 major groups: melanoma and nonmelanoma skin cancers. The latter group consists primarily of basal cell carcinomas and squamous cell carcinomas. Roughly $1,200,000$ nonmelanoma skin cancers develop annually in the United States. ${ }^{2}$ These tumors are rarely fatal, but are considered to be fast growing tumors that if neglected may be locally and functionally destructive.

In contrast, melanoma represents $5 \%$ of all diagnosed cancers in the United States, $15 \%$ of which prove to be fatal. ${ }^{3}$ Although melanoma is seen more with increasing age, it is the most frequent cancer plaguing women aged 25 to 29 years, and the second most frequent cancer afflicting women aged 30 to $34 .^{2}$ Tumor depth is the most important prognostic indicator for melanoma, thus early recognition and management are imperative for improved therapeutic outcome.

Although the nonmelanoma and melanoma skin cancers encompass the vast majority of skin cancers, there is a large number of other malignancies of the skin that are less commonly confronted by the clinician. Neoplasms of the skin classically have been divided into those that differentiate from the epidermis, dermis, adnexal structures of the skin, and those derived systemically. This review focuses on the most frequent malignant neoplasms, and divides them into those that are classically designated nonmelanoma skin cancers (also known as keratinocytic tumors), melanoma, and other less common skin cancers of the skin. An extensive list of skin malignancies is provided in Box $\mathbf{1}$.

\footnotetext{
a Department of Dermatology, University of Texas Southwestern Medical Center, 5323 Harry Hines Boulevard, Dallas, TX 75390-9069, USA

b Department of Dermatology, University of Miami L. Miller School of Medicine, 1600 NW 10th Avenue, Miami, FL 33136, USA

c Cockerell and Associates Dermatopathology Laboratories/Dermpath Diagnostics, 2330 Butler Street Suite 115, Dallas, TX 75235, USA

* Corresponding author. Cockerell and Associates Dermatopathology Laboratories/Dermpath Diagnostics, 2330 Butler Street Suite 115, Dallas, TX 75235.

E-mail address: ccockerell@dermpathdiagnostics.com (C.J. Cockerell).
} 
Box 1

Malignant skin neoplasms

1. Keratinocytic tumors
a. basal cell carcinoma
b. squamous cell carcinoma
c. Bowen's disease
d. bowenoid papulosis
e. actinic keratosis
f. keratoacanthoma

2. Melanocytic tumors
a. superficial spreading melanoma
b. nodular melanoma
c. lentigo maligna
d. acral-lentiginous melanoma
e. desmoplastic melanoma
f. nevoid melanoma
g. amelanotic melanoma

3. Appendageal tumors
a. tubular carcinoma

b. microcystic adnexal carcinoma

c. porocarcinoma

d. spiradenocarcinoma

e. hidradenocarcinoma

f. mucinous carcinoma

g. digital papillary carcinoma

h. apocrine carcinoma

i. Paget's disease and extramammary Paget's disease

4. Soft tissue tumors

a. dermatofibrosarcoma protuberans

b. Kaposi sarcoma

c. angiosarcoma

5. Neural tumors

a. primary malignant peripheral neuroectodermal tumor

b. Merkel cell carcinoma

6. Cutaneous lymphomas 


\section{NONMELANOMA SKIN CANCERS (KERATINOCYTIC TUMORS)}

Actinic Keratosis (Solar Keratosis)

Actinic keratosis was first identified as "keratoma senilis" by Freudenthal in 1926, and later more fully described and renamed "actinic keratosis" by Pinkus in 1958. 4,5 The term "actinic keratosis" literally means a keratotic (thickened, scaly) growth caused by damage induced by a ray, presumably electromagnetic irradiation including sunlight. Other sources of radiation such as artificial light sources, including tanning beds and ultraviolet irradiation, may result in actinic keratosis as well. These lesions are considered to be premalignant squamoproliferative lesions, and some investigators have postulated that they may actually represent an intraepithelial form of squamous cell carcinoma kept in check by immune surveillance of the body.

Actinic keratosis is one of the most common skin conditions managed by the dermatologist. There are more than 2 million cases diagnosed yearly. In Australia, the estimated rates of actinic keratosis in adults over 40 years old ranges from $40 \%$ to $60 \%{ }^{6}$ It is estimated that up to $25 \%$ regress spontaneously but $0.1 \%$ to $10 \%$ may undergo malignant transformation to squamous cell carcinoma. ${ }^{7-9}$

The frequency of actinic keratosis correlates with cumulative UV exposure. High-risk populations include the elderly and people receiving immunosuppressive therapy, psoralen plus ultraviolet A therapy, and arsenic exposure. Outdoor workers have higher annual exposure to ultraviolet light, thus constituting an occupational risk in a subset of patients. $^{10-12}$

In solid organ transplant patients, actinic keratosis occurs significantly earlier (54 vs 70 years). ${ }^{13}$ Furthermore, it has been suggested that in patients with organ transplants and actinic keratosis, there is a higher accelerated progress of squamoproliferative neoplasms to invasive squamous cell carcinoma. ${ }^{14}$

Actinic keratosis clinically presents as rough, pink, but circumscribed epidermal lesions ( $<1 \mathrm{~cm}$ in diameter), typically found on areas of the body exposed to sunlight (Fig. 1); it can also present with brown pigmentation, and may form cutaneous horns (Fig. 2). Patients of fair complexion and chronic sun exposure most commonly have actinic keratosis, but it can occur in patients of any skin type. Due to the variety of clinical presentations, other lesions such as melanomas, squamous cell carcinomas, and warts must be excluded. It is more difficult to separate actinic keratosis from other skin neoplasms in patients with multiple actinic keratosis. Furthermore it is difficult, if not impossible, to determine which actinic keratosis will eventually become a squamous cell carcinoma.

Actinic keratoses represent focal areas of abnormal keratinocyte proliferation with loss of orderly maturation of keratinocytes. There are atypical keratinocytes characteristically involving the lower portions of the epidermis with overlying parakeratosis (Fig. 3). Cells show hyperchromaticity of nuclei, and atypical mitotic figures. Five classic histologic variants have been described: hypertrophic, atrophic, bowenoid, acantholytic, and pigmented. Histologic overlap of more advanced actinic keratosis and squamous cell carcinoma in situ is frequent, and some investigators have postulated a revised histologic grading system similar to that of cervical intraepithelial neoplasms (squamous cell carcinoma in situ AK type or keratinocyte intraepithelial neoplasia). Identical gene mutations (ie, p53) have been linked to both actinic keratosis and squamous cell carcinoma, supporting the hypothesis that actinic keratosis is indeed an early squamous cell carcinoma in situ. ${ }^{15}$ This linkage would potentially allow grading of these lesions, and help improve the understanding of their biologic behavior.

Actinic keratoses may be treated for cosmetic reasons or for relief of associated symptoms, but the most compelling reason for treatment is to prevent squamous cell carcinomas. Several treatment modalities have been described including 


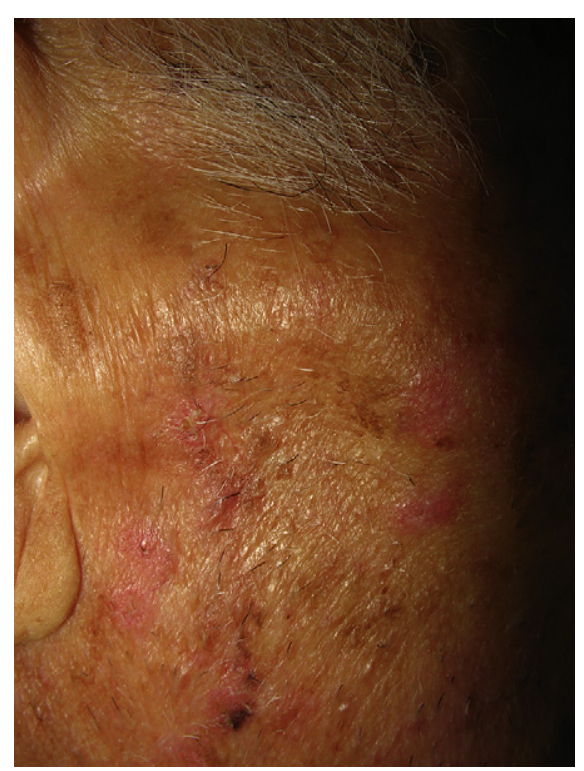

Fig. 1. Actinic keratosis. There are multiple pink scaly papules. Multiple lesions are frequently seen, and it is difficult to distinguish more advanced lesions from squamous cell carcinoma.

cryotherapy, photodynamic therapy, and topical therapies. Choice of treatment depends on patient preference and understanding of treatment, comorbidity, and cost. Whereas cryotherapy and other surgical therapies (eg, laser therapy, dermabrasion, and so forth) are suitable for treating solitary or few actinic keratosis, more widespread change requires topical treatment or photodynamic therapy (PDT). Cryotherapy using liquid nitrogen is the most common modality for treating actinic keratoses. The procedure is highly effective, with reported cure rates between $75 \%$ and $99 \% .{ }^{16}$ Potential adverse effects include infection, hypo- or hyperpigmentation, scarring, and hair loss; however, serious reactions are rare. Topical fluorouracil is an established treatment for actinic keratosis (Fig. 4). Fluorouracil acts by inhibiting DNA synthesis. Another topical treatment is imiquimod, which is an immunomodulator

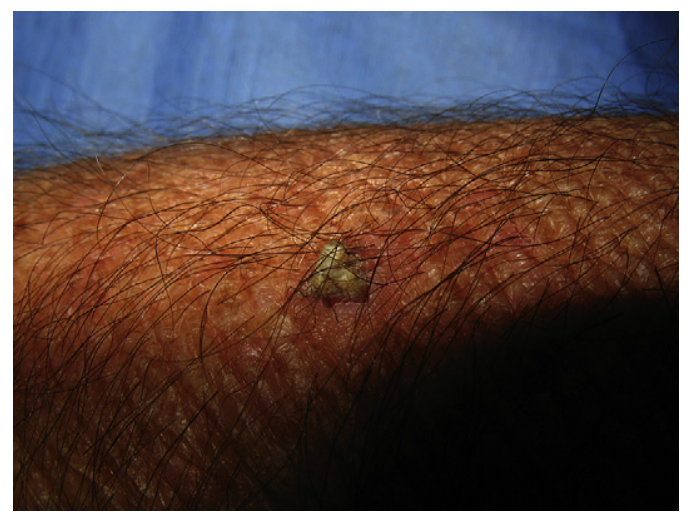

Fig. 2. A cutaneous horn (Actinic Keratosis) There is an indurated scaly horn present on the surface of a pink papule. 


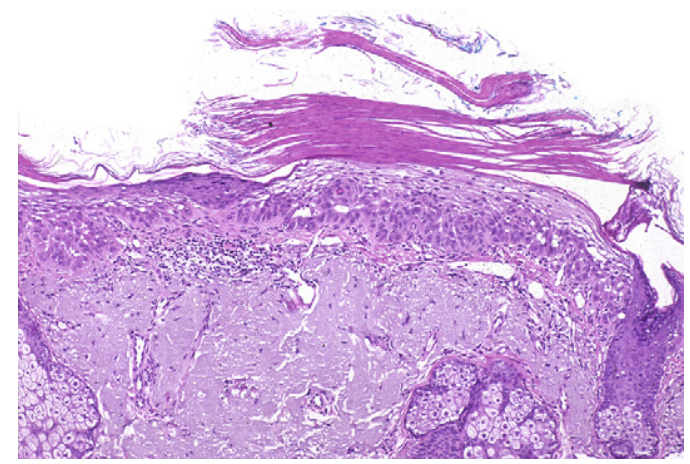

Fig. 3. Histologic image of actinic keratosis under light microscopy (original magnification $\times 20$ ). There are characteristic focal areas of parakeratosis, with loss of the underlying granular layer, and a slightly thickened epidermis. There is some mild downward growth of the basal layer and cytologically atypical keratinocytes. Extensive solar elastosis is commonly observed in the dermis. If solar elastosis is not evident in a suspected actinic keratosis, other lesions that mimic actinic keratosis should be considered in the differential diagnosis.

that acts by upregulating the production of tumor necrosis factor- $\alpha$ and other proinflammatory cytokines in the skin via Toll-like receptors. Fluorouracil is approved in both the United States and Europe for treating actinic keratosis, with reported clearance rates between $53.7 \%$ and $70 \% .{ }^{17}$ Topical diclofenac has also been suggested to improve clinical appearance of actinic keratosis in several studies. In a phase 4 study, $78 \%$ of patients had $75 \%$ reduction in actinic keratosis after 12 weeks of treatment with topical diclofenac. However, its efficacy has not been confirmed histologically, and there is a need for further studies. Photodynamic therapy involves applying a photosensitizing agent to each actinic keratosis, followed by exposure to light of a specific wavelength; this leads to cell death. This method has been found to be superior to cryotherapy and 5-fluorouracil (5-FU) in treating extensive actinic keratosis, with a reported cure rate between $69 \%$ and $93 \%$. PDT using both blue light and red light is approved by the Food and Drug Administration (FDA) for treating nonhyperkeratotic actinic keratosis on the face and scalp. ${ }^{16}$

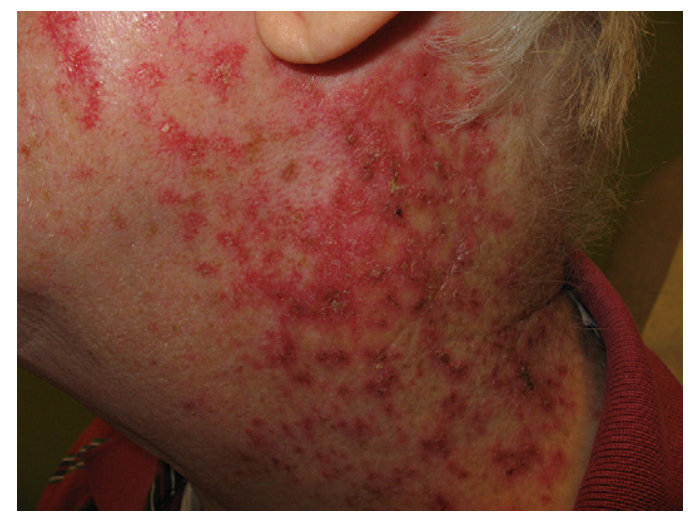

Fig. 4. Clinical presentation of a patient who received 2 weeks of topical 5-fluorouracil twice daily. There are multiple pink scaly papules and areas of erosion. Lesions resolve 1 month after therapy. Lesions that persist after therapy may represent early squamous cell carcinomas and should be managed appropriately. 


\section{Keratoacanthoma}

Keratoacanthoma was first described as a "crateriform ulcer of the face" by sir Jonathan Hutchinson, and due to its considerable acanthosis was coined "keratoacanthoma" during the post-World War II era by Freudenthal of Wroclaw. ${ }^{18,19}$

The incidence of keratoacanthoma is difficult to know because $50 \%$ of cases spontaneously involute. ${ }^{20}$ Data on keratoacanthoma incidence does not take this into account. Keratoacanthomas occur between the ages of 50 and 69 years, with rare presentation before the age of $20 .{ }^{21,22}$ The incidence is slightly increased in males. ${ }^{22}$

The typical keratoacanthoma is a solitary lesion found on the lower lip, cheek, nose, eyelid, hands, or neck (Fig. 5). ${ }^{23}$ The lesion is generally characterized by 3 distinct stages of maturation. During the primary stage the tumor grows rapidly to about 10 to $25 \mathrm{~mm}$ in size. ${ }^{24}$ This stage lasts approximately 2 months. During the secondary stage the lesion stops growing and presents as a keratin-containing domelike structure. During the tertiary stage, $50 \%$ of the lesions regress and expel their keratin contents. This stage lasts approximately 1 month. ${ }^{20,25}$ One-fifth of keratoacanthomas studied have evolved into malignant lesions metastasizing into perivascular, perineural, intravascular, and lymphatic areas. ${ }^{26-28}$

During the proliferative or primary stage, proximal hair follicles localize the invagination of the epidermis with a keratin inclusion. This lesion is characterized by hyperkeratosis, acanthosis, and a thick stratum granulosum with keratohyalin granules. In addition, mitotically active, possibly atypical epidermal cells migrate from the hair follicles toward the eccrine sweat glands. Perineural and intravascular invasion are considered benign, while the prognostic impact of invasion below the level of eccrine sweat glands is under debate. During the fully developed, secondary stage, a lip of epidermal cells extends around a keratin-filled crater, with many areas of keratinization characterized by an eosinophilic and glassy-finished look. Microabscesses with associated neutrophils, horn pearls, and a mixed dermal accumulation of lymphocytes, histiocytes, eosinophils, and plasma cells are common. During the involutional, or tertiary stage, keratinization of the base of the crater leads to its flattening-out. The dermal infiltrate of the secondary stage is characterized predominantly by histiocytes that form a granuloma-like structure against the keratinized base. Fibroblasts beneath the base proliferate, causing a gradual flattening of the base and expulsion of the contents of the lesion including any atypical remnants. Due to the histologic and

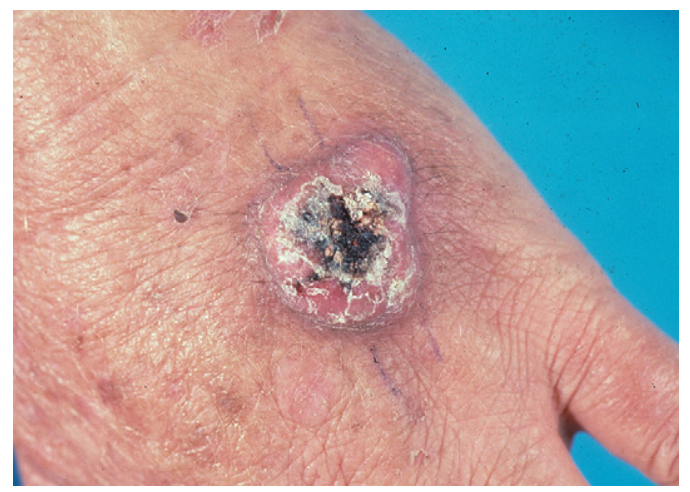

Fig. 5. A keratoacanthoma. There is a large pink plaque with raised borders and a crateriform ulcer in the center of the lesion. Crateriform squamous cell carcinomas may present clinically with similar findings. 
clinical findings, many consider this a variant of squamous cell carcinoma. ${ }^{24}$ Therapy for keratoacanthomas is primarily destruction or excision. Management is essentially similar to that of squamous cell carcinomas and basal cell carcinomas, and is discussed in a later section.

\section{Squamous Cell Carcinoma in Situ and Bowen's Disease}

Squamous cell carcinoma in situ is an "intraepidermal carcinoma" made up of atypical keratinocytes throughout the full thickness of the epidermis. Bowen's disease is a term initially historically used for squamous cell carcinoma in situ of "non-sunexposed" skin. At present, however, it is generally accepted that Bowen's disease and squamous cell carcinoma of the skin in situ are synonymous.

The etiology of squamous cell carcinoma in situ is similar to actinic keratosis, and includes UV irradiation from sunlight or other sources. Squamous cell carcinomas are also frequently associated with human papilloma virus (HPV). Those of genital areas are most commonly associated with HPV-16 and HPV-18. Nongenital squamous cell carcinoma in situ may also be associated with HPV, those most commonly cited in the literature being HPV-2, HPV-16, HPV-34, and HPV-56. A retrospective study of patients with squamous cell carcinoma in situ showed that $19 \%$ were immunocompromised, and these patients were approximately 10 years younger, had more lesions, and had a higher rate of recurrence (9\% vs 3\%). ${ }^{29}$ Roughly $3 \%$ to $11 \%$ of squamous cell carcinomas in situ may become invasive squamous cell carcinomas, and thus present invasive malignant potential. ${ }^{30,31}$

These lesions present clinically as pink, well-defined, erythematous papules and plaques anywhere on the body including the trunk, eyelids, hands, feet, face, and genital area. The lesions may have scale, and the patient often inform the physician that the lesion has bled in the past.

Squamous cell carcinoma in situ histologically shows full-thickness involvement of atypical keratinocytes throughout the epidermis, and may involve the epidermis of adnexal structures such as the hair follicles. Increased mitotic activity is evident, as well as disorganization of the orderly maturation of the epidermis with loss of the granular layer. Necrotic keratinocytes are frequently observed. In the superficial dermis there may be lymphocyte aggregates (Fig. 6). ${ }^{32}$ Bowenoid papulosis is likely a variant of squamous cell carcinoma in situ that clinically appears on the genitals, and appears more as a verrucous simulating condyloma accuminatum (Fig. 7). Bowenoid papulosis histologically has features of condyloma accuminatum but also keratinocyte atypia similar to that found in squamous cell carcinoma in situ. In general these tumors are more indolent than squamous cell carcinoma in situ, but invasive bowenoid papulosis has been reported.

Multiple therapeutic options are available for treatment of squamous cell carcinoma in situ. 5-FU has been used topically for treatment of squamous cell carcinoma in situ. 5 -FU is usually applied once or twice daily as a $5 \%$ cream for a variable period of time (between 1 week and 2 months) to achieve disease control, and repeated if required at intervals. Imiquimod has been used as a 5\% cream. Imiquimod has both anti-HPV and antitumor effects, and is therefore potentially useful for HPV-associated Bowen/bowenoid papulosis as well as for non-HPV-associated Bowen disease. The best evidence currently available is a single small study that demonstrated $73 \%$ histologically proven resolution with imiquimod. ${ }^{33}$ Cryotherapy seems to have a good success rate with adequate treatment (recurrences less than $10 \%$ at 12 months), but healing may be slow for broad lesions and discomfort may limit treatment of multiple lesions. Curettage with electrocautery is also described, with a wide range of cure rates. Although it is logical that excision should be an effective treatment, the evidence base is limited. 


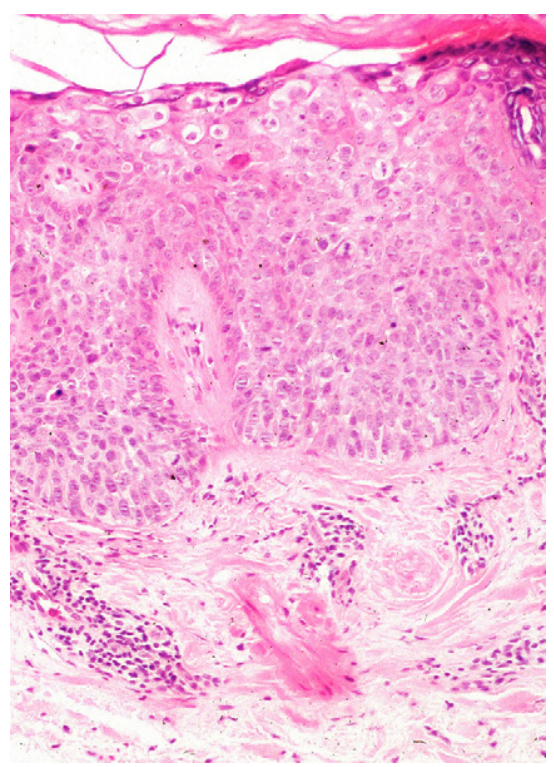

Fig. 6. Histologic image of squamous cell carcinoma in situ under light microscopy (original magnification $\times 20$ ). There is full-thickness involvement of the epidermis and manifold involvement of the pilosebaceous units. There is disorderly maturation of the keratinocytes and presence of many mitoses and dyskeratotic keratinocytes throughout the epidermis. The basement membrane is not compromised, and the lesion is limited to the epidermis.

Mohs micrographic surgery (MMS) has become the recommended treatment for digital and for some cases of genital (especially penile) squamous cell carcinoma in situ, due to its tissue-sparing benefits. Previous studies on PDT suggested an initial clinical clearance rate of $80 \%$ to $100 \%$ (most around $90 \%$ ) with 1 or 2 treatments, and a recurrence rate of about $0 \%$ to $10 \%$ at 12 months. This modality requires the activation of a photosensitizer, usually a porphyrin derivative, by visible light. All of the aforementioned treatments have some advantages and disadvantages, which

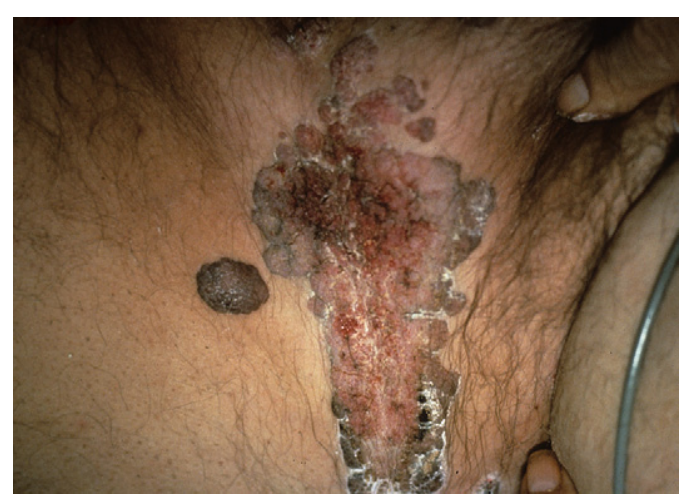

Fig. 7. Bowenoid papulosis. There is a large multifocal verrucous brown plaque with surrounding brown/red papules. These lesions tend to have irregular borders and often are confused with melanoma. 
are dictated by lesional factors (size, number, site, potential for healing, or functional impairment), general health issues, availability, and cost. ${ }^{34}$

\section{Squamous Cell Carcinoma}

Squamous cell carcinoma is the second most common cancer in the United States, but causes more deaths than basal cell carcinoma. The American Cancer Society estimated that at least $20 \%$ of cases of skin cancer in the year 2000 were squamous cell carcinomas and in 2008, over 1 million new cases of skin cancer were estimated. ${ }^{3}$ Squamous cell carcinoma is more common in older, fair-skinned individuals, and is a result of chronic UV exposure. The pathomechanism for the development of squamous cell carcinoma is complex and multifactorial, and requires both genetic predisposition and environmental exposures. The role of UV damage to the DNA of keratinocytes is considered the most important contributing carcinogenic factor, as $80 \%$ of squamous cell carcinomas occur on sun-exposed areas of the body. Although both UVA and UVB radiation plays a role in the formation of squamous cell carcinoma, it seems that UVB rays are the more important contributing factor. Furthermore, it is known that the incidence is increasing, and that this may due to the depleting ozone layer, further migration of aging populations to areas of warmer climate, and the increased use of tanning beds. ${ }^{35}$ Duration of immunosuppression in solid organ transplanted patients has been directly correlated with the development of squamous cell carcinoma in this patient subset. ${ }^{36-38}$ The incidence increased from $5 \%$ at 2 years, to $10 \%$ to $27 \%$ at 10 years, to $40 \%$ to $60 \%$ at 20 years, and it was found to be linked to the associated immunosuppression regimen. These regimens allow for the production of cytokines that promote tumor growth and proliferation. ${ }^{14}$ HPV plays a role in the pathogenesis of squamous cell carcinoma in both immunocompetent and immunosuppressed patients. In genital squamous cell carcinoma HPV-16 or HPV-18 have been implicated, and in head and neck squamous cell carcinoma, HPV-16 is a risk factor. Chronic inflammatory conditions may also result in keratinocyte transformation to squamous cell carcinoma. These conditions include chronic venous ulcers, discoid lupus erythematosus lesions, erosive lichen planus, and lymphedema. Any changes in the clinical appearance of a chronic cutaneous inflammatory condition, especially increased induration or ulceration, should trigger the physician to consider transformation to squamous cell carcinoma and pursue further diagnostic studies including a skin biopsy.

For most fair-skinned individuals, squamous cell carcinoma will develop on skin within a preexisting area of actinic keratosis. The clinical presentation may vary from a small, pink, erythematous, scaly papule to a large, ulcerated, and indurated plaque (Fig. 8). If the squamous cell carcinoma is sufficient in size, patients may note pain, bleeding, or other peripheral neural symptoms reflecting perineural spread. The clinical differential diagnosis includes actinic keratosis, keratoacanthoma, basal cell carcinoma, and melanoma. The definitive diagnosis is usually rendered on pathologic evaluation of a lesional skin biopsy specimen. Squamous cell carcinomas of mucosal surfaces tend to be far more aggressive, and may present with regional lymph node involvement. A lymphatic examination is mandatory for any invasive lesion and for patients with prior invasive or high-risk squamous cell carcinomas. For larger lesions and lesions involving the mucosal surfaces, patients should be staged according to the American Joint Committee on Cancer criteria.

Squamous cell carcinomas consist histologically of nests of atypical squamous epithelial cells intermixed with normal squamous cells, which arise from the epidermis and extend into the dermis. Characteristics of these atypical cells include a more extensive range of size and shape, hyperplasia and hyperchromasia of nuclei, 


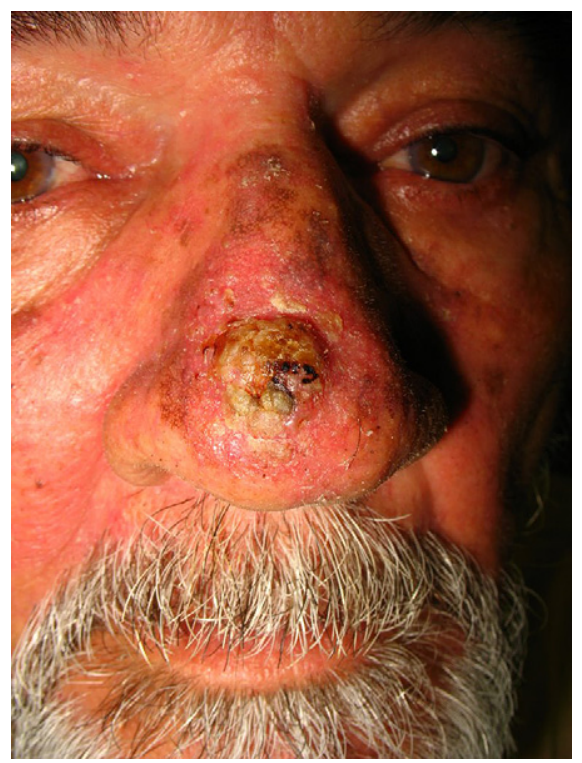

Fig. 8. An invasive squamous cell carcinoma. There is a large crusted plaque with surrounding ill-defined pink scaly plaque.

increased abnormal mitotic figures, and loss of intercellular bridges. Keratinization is common in squamous cell carcinomas (Fig. 9). Most squamous cell carcinomas arise at a site with surrounding chronic sun damage, showing solar elastosis as well as actinic keratosis adjacent or within the squamous cell carcinomas. Some investigators have proposed histologic criteria for determining prognosis, but currently there are no definitive criteria. Many have suggested that prognosis be based on histologic squamous cell carcinoma variant, depth of invasion, or whether there is perineural

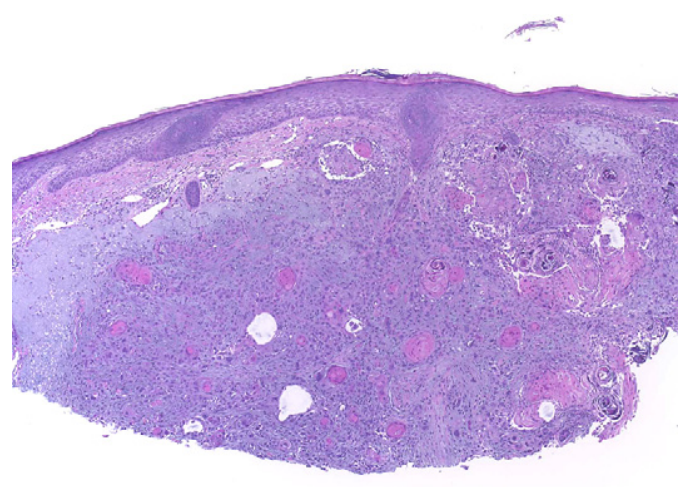

Fig. 9. Histologic image of an invasive squamous cell carcinoma under light microscopy (original magnification $\times 10$ ). There is a large nest of squamous epithelial cells that arises from the epidermis and extends deep into the dermis. Cells are cytologically atypical, are large, and present with many mitotic figures. There is keratinization and squamous pearls in this lesion. 
involvement, but this has yet to be generally accepted. ${ }^{39}$ Therapy and management of squamous cell carcinomas is discussed later.

\section{Basal Cell Carcinoma}

In 1827 Arthur Jacob published "Observations respecting an ulcer of a peculiar character which affects the eyes and face." 40 What he described in his article later came to be known as basal cell carcinoma, so named because from a histologic perspective it looks similar to basal cells of the epidermis. Basal cell carcinoma is the most common malignancy occurring in humans. The American Cancer Society estimated about $75 \%$ of cases of skin cancer in the year 2000 were basal cell carcinomas and in 2008, over 1 million new cases of skin cancer were estimated. ${ }^{3}$ Basal cell carcinoma is most common in fair-skinned individuals (those who burn easily and tan poorly), although it may be found in patients with darker skin types, including those of African descent. ${ }^{41}$ Previous articles have suggested that childhood exposure to UV radiation is the primary cause of basal cell carcinoma, and adult exposure does not have as much of an impact. ${ }^{42}$ Intermittent chronic light exposure, rather than continuous light exposure, is more closely associated with basal cell carcinoma. ${ }^{43}$ The probable range of wavelength of UV exposure that contributes to all nonmelanoma skin cancers includes 293, 354, and $380 \mathrm{~nm} .{ }^{44}$ There is also a strong inverse correlation between latitude and the development of basal cell cancer. ${ }^{45}$ More recently 2 vitamin D polymorphisms have been associated with nonmelanoma skin cancers and malignant melanoma, suggesting that their development may be somehow associated with vitamin $D$ metabolism. ${ }^{46}$ As with squamous cell cancer, basal cell carcinoma incidence increases in patients with solid organ transplantation receiving concomitant immunosuppressive therapy. ${ }^{36-38}$

Most basal cell carcinomas are found on the head and neck; however, some may be found in non-sun-exposed areas of the body. The vast majority (60\%) of basal cell carcinomas are noduloulcerative or "rodent ulcers." These lesions begin as small, reddish, translucent nodules with telangiectasias (Fig. 10). As the lesion grows, the center may ulcerate, leaving behind the classic "rolled borders." If the lesion is not treated in its earlier stages it can lead to destruction of underlying tissue, including intracranial invasion. ${ }^{47}$ Although the cancer is not known to be associated with a high mortality, there have been a few cases of metastasis to the central nervous system and the bone. ${ }^{48}$ These cases are extremely rare, and it is much more common for basal cell carcinomas to be locally aggressive than systemically involved.

Most variants of basal cell carcinomas retain some characteristics of normal basal cells; however, they differ due to a lower cytoplasm to nuclear ratio and absence of intercellular bridges (Fig. 11). Different basal cell carcinomas vary in terms of change in cellular population and cell morphology. It is currently assumed that pluripotential stem cells have a high potential to convert to basal cell carcinoma when exposed to excessive sunlight or have p53 gene mutations. Four major subclasses exist: nodular, superficial, pigmented, and morpheaform. The nodular form shows palisading of nuclei, clefts between epithelium and the stroma, and a specialized stroma. The superficial form shows horizontally arranged lobules of atypical basal cells in the papillary dermis that have broad-based connections with the epidermis, surrounded by a thin stroma filled with lymphocytes and histiocytes. The pigmented form is similar to the nodular form, with the addition of melanocytes intermixed with basal cells and melanin within the cancer cells and stromal macrophages. The morpheic form has no connection to the epidermis, and usually presents as islands of neoplastic basal cells surrounded by a dense collagen-filled stroma. ${ }^{49}$ The latter variant has 


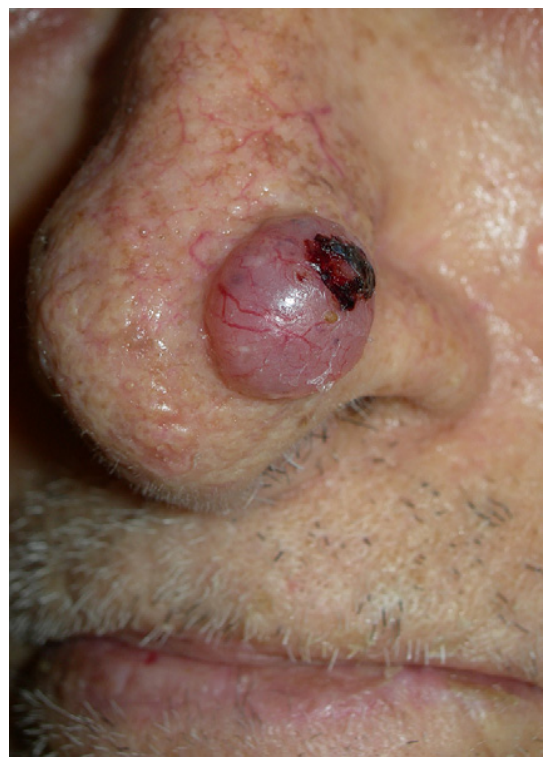

Fig. 10. A nodular basal cell carcinoma. There is a large nodule with telangiectasis and "pearly" appearance. The lesion is centrally ulcerated. Amelanotic melanoma and Merkel cell carcinoma may have similar clinical appearance.

a higher associated recurrence rate after surgical therapy compared with other variants.

The clinician should be particularly aware of patients with certain syndromes who are more predisposed to developing basal cell carcinoma frequently on non-sun-exposed skin. Xeroderma pigmentosum, an autosomal recessive condition in which repair mechanisms for UV-damaged genes are inhibited, is associated with a 1000-fold

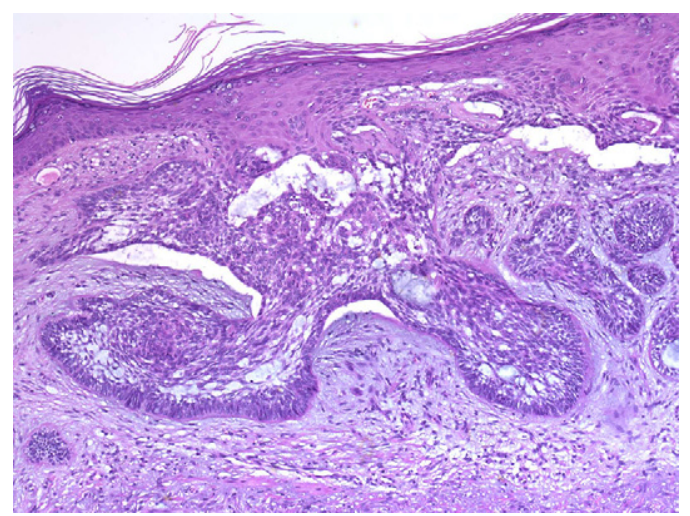

Fig. 11. Histologic image of a basal cell carcinoma under light microscopy (original magnification $\times 20$ ). There are islands of basaloid cells, with palisading of the cells at the periphery and disorganized arrangement of cells within the tumor. The basaloid islands typically arise from the epidermis. Frequent histologic findings observed in this lesion are clefting of the tumor from the surrounding stroma and increased mitotic rate of cells within the tumor. 
increase in skin and eye cancers, many of which are basal cell carcinomas. ${ }^{50}$ Gorlin syndrome, also known as nevoid basal cell carcinoma syndrome, is a hereditary condition characterized by odontogenic keratocysts of the jaws, hyperkeratosis of palms and soles, and skeletal abnormalities. It was determined recently that the "Hedge Hog" pathway, including a PTCH gene mutation (this gene is involved in inhibition of a cascade molecular event that results in cell proliferation), is involved in the development of basal cell carcinomas, and this gene mutation is implicated in the pathogenesis of Gorlin syndrome. Other syndromes associated with melanin deficiency such as Rasmussen, Rombo, and albinism are associated with an increased risk of basal cell carcinoma as well. ${ }^{51}$

\section{Treatment of Basal Cell Carcinoma and Squamous Cell Carcinoma}

The most frequently used method for the treatment of nonmelanoma skin cancer is surgical excision of the tumor. Surgical approaches include conventional excision, MMS, electrodessication and curettage, and cryosurgery. MMS is considered by some as the "gold standard" for the treatment of a range of nonmelanoma squamous cell cancers because this method provides the most complete histologic analysis of tumor margins, the highest cure rate, and preservation of the maximal amount of normal tissue by removing the tumor with the smallest margin necessary. ${ }^{52} \mathrm{MMS}$ is a technique in which serial horizontal sections of tumor are removed, mapped, processed by frozen section in an en-face fashion, and analyzed microscopically. The entire deep and peripheral margins are examined by the surgeon and immediate reexcision of the residual tumor region is performed until the area is tumor free. Table 1 shows the indications of MMS in treating nonmelanoma skin cancer. Excision is the most common therapy for treating nonmelanoma squamous cell cancer, and is useful for treating low-risk tumors because it provides acceptable cure rates and is costeffective. $^{53}$ This method allows for histopathologic examination of the tissue, and although $100 \%$ of the margin is not examined, $95 \%$ of low-risk tumors will be adequately excised by removal of the tumor with a 4-mm margin. The cure rates for squamous cell carcinoma and basal cell cancer are $92 \%$ and $95 \%$, respectively. Curettage and electrodessication is often used to treat superficial nonmelanoma squamous cell cancer, and relies on the textural differences between tumor cells and the surrounding normal tissue. This technique does not permit histologic margin analysis. The method is also technique dependent and not appropriate for higher-risk tumors such as morpheaform, but it is cost-effective and rapid to perform. Curettage and electrodessication is not suitable for treating recurrent tumors, lesions larger than $2 \mathrm{~cm}$ in diameter, tumors extending into the fat, tumors at sites of high risk for

\begin{tabular}{|c|c|}
\hline Indicated & Preferred \\
\hline $\begin{array}{l}\text { Tumor in locations with high rates of } \\
\text { recurrence (eg, midface and ears) }\end{array}$ & $\begin{array}{l}\text { Tumor in functionally and cosmetically unique } \\
\text { areas such as the nose, lips, and eyelids }\end{array}$ \\
\hline $\begin{array}{l}\text { Tumors with aggressive histologic } \\
\text { growth patterns (eg, morpheaform, } \\
\text { infiltrative, and sclerosing BCC) }\end{array}$ & $\begin{array}{l}\text { Tumor in lower extremities where healing can be } \\
\text { prolonged and tissue preservation is } \\
\text { advantageous }\end{array}$ \\
\hline \multicolumn{2}{|l|}{ Recurrent tumor } \\
\hline \multicolumn{2}{|l|}{ Tumor greater than $2 \mathrm{~cm}$ in size } \\
\hline Tumors with ill-defined clinical margins & \\
\hline
\end{tabular}


recurrence, or lesions with ill-defined borders. Curettage and electrodessication has a recurrence rate of $4.5 \%$ to $17.6 \% .^{52}$ Nonmelanoma squamous cell cancer can be treated using ionizing radiation as either a primary or adjuvant therapy. Although radiation therapy is effective, its use is limited because of the side effects induced; hence, radiation therapy can be used in certain patients who are not surgical candidates. Newer noninvasive options for nonmelanoma squamous cell cancer include topical chemotherapeutics, biological immune response modifiers, retinoids, and photodynamic therapy, which can be used particularly in patients with superficial tumors. Topical 5-FU application has been limited to treating superficial or squamous cell carcinoma. Topical imiquimod similarly is only effective against superficial basal cell carcinoma, small nodular basal cell carcinoma, and squamous cell carcinoma in situ. Imiquimod is FDA-approved only for actinic keratosis and superficial basal cell carcinoma. Studies have demonstrated that application of imiquimod 5 days per week for 6 weeks results in $88 \%$ histologic clearance rate using Aldara (imiquimod) $5 \%$ cream. ${ }^{54}$ Photodynamic therapy is effective in treating squamous cell carcinoma in situ and superficial basal cell carcinomas. Photodynamic treatment of nodular basal cell carcinoma has demonstrated complete responses in $90 \%$ of patients, with $74 \%$ remaining clear after 2 years. ${ }^{55}$ Photodynamic therapy is limited by the depth of penetration of the topical photosensitizers and should not be used to treat thick tumors, tumors with certain aggressive histologic subtypes (eg, morpheaform basal cell carcinoma), or recurrent cancers. Systemic retinoids that are derivatives of vitamin A have a proven chemopreventative effect in reducing the risk of developing squamous cell carcinoma and basal cell carcinoma. The mechanism of action is thought to occur via induction of apoptosis, impedance of tumor proliferation, or stimulation of differentiation during the tumor promotion phase of carcinogenesis. These agents, however, are typically not effective in treating existing tumors. ${ }^{56}$

\section{MELANOMA}

\section{Malignant Melanoma}

The American Cancer Society estimated over 62,000 newly diagnosed cases of melanoma in $2008 .^{3}$ Cutaneous melanoma may have myriad clinical appearances with histopathological correlates. Whereas most early lesions demonstrate the "ABCDEs" (Asymmetry, Borders, Color, Diameter, and Evolving) that have been described, many others may be unusual and manifest either some or none of these features. Most are patches, plaques, nodules or tumors, and are greater than $6 \mathrm{~mm}$ in diameter when diagnosed, but lesions much smaller than this are well recognized.

The risk factors associated with the development of malignant melanoma are also multifactorial, with both genetic and environmental factors playing a role in its pathogenesis. As with the nonmelanoma skin cancers, patients with fair skin color, blond or red hair, and who burn easily are more at risk than other patients. Details go beyond the scope of this review, but repeated acute sun exposure that has resulted in blistering sunburns during childhood or adolescence increases the risk for melanoma. ${ }^{57}$ The effect of chronic sun exposure is more controversial, and there are conflicting data regarding the association between long-term chronic sun exposure and melanoma development. ${ }^{58}$ The effects of UV radiation on melanocyte mutations is less understood than that of nonmelanoma skin cancers. More recently, tanning salons have been implicated in the development of malignant melanoma, and public education should be paramount in decreasing the incidence of melanoma in patients who use tanning beds. ${ }^{59,60}$

Malignant melanoma has been classified based on clinicopathological characteristics. The most common is the superficial spreading melanoma, followed by lentigo 
maligna (LM) melanoma, nodular melanoma, acral lentiginous melanoma (Fig. 12), desmoplastic melanoma, and other miscellaneous variants. LM and superficial spreading melanoma are both in situ melanomas, and are histologic variants of melanoma confined to the epidermis and the epidermis of adnexal structures. The other variants contain dermal components of the melanoma and, as a result, worse prognosis.

Although most malignant melanomas are pigmented, less than $2 \%$ of melanomas are amelanotic, and these pose the most difficulty in clinical diagnosis. ${ }^{61}$ These lesions are pink or skin-colored patches, plaques, or nodules that may be ulcerated; they are often mistaken for pyogenic granuloma, basal cell carcinoma, nevi, or fibromas. Desmoplastic melanoma is a rare variant that is notoriously difficult to diagnose clinically and histologically (Fig. 13). Desmoplastic melanoma usually presents subtly as a pigmented or skin-colored indurated patch, papule, or plaque on sun-exposed skin. Lesions are described clinically as "fibroma" or "scar."

The histopathological diagnosis of melanoma has an extensive and detailed history. A "unifying concept" regarding the histologic diagnosis of melanoma by Ackerman has been proposed and used by the vast majority of pathologists. ${ }^{62}$ Both architectural and cytologic criteria were established, and from these criteria the diagnosis of melanoma was rendered. The definitive diagnosis of melanoma often cannot be made, as all histologic criteria have not been fulfilled. This area of more "atypical melanocytic lesions" that do not fulfill criteria for melanoma is an ongoing area of research and investigation, and highlights the difficulty in diagnosing certain melanocytic lesions. ${ }^{63}$

It cannot be stressed enough that the diagnosis rendered by pathologic examination and the prognosis is dependent on appropriate and adequate sampling by the clinician. ${ }^{64}$ Diagnosis is dependent on sampling the correct area of the lesion (ideally the whole pigmented lesion should be sampled) and examination of the entire breadth of the lesion. The lesion thickness as established by light microscopic examination is the most important determinant of prognosis, thus if the biopsy is transected at the base of the tumor, prognosis cannot be fully determined. Extent of anatomic tumor invasion by the primary lesion predicts the 10-year survival probability (Table 2). ${ }^{65}$ Furthermore, this information is used to establish staging according to the American Joint Committee on Cancer Staging System. ${ }^{66}$ Once the lesion is greater than $1 \mathrm{~mm}$ in depth, it has been determined that histologic observation of ulceration is a significant

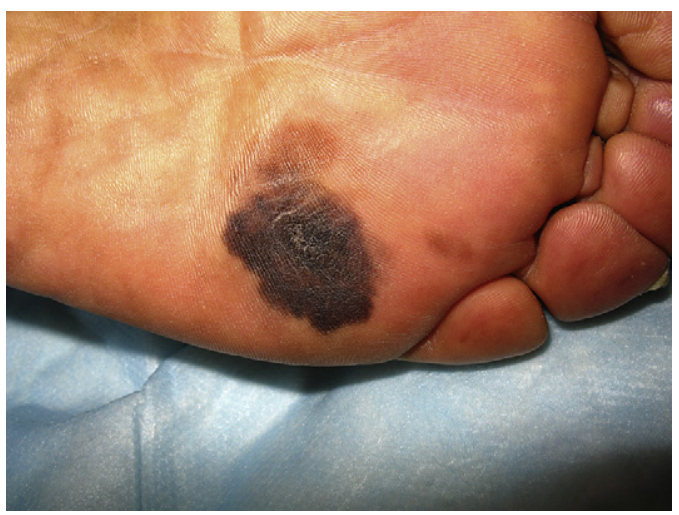

Fig.12. An acral melanoma. There is a large $(>6 \mathrm{~mm})$, asymmetric, ill-defined brown patch on the sole of the patient's foot. This appearance is characteristic of advanced acral melanomas. 


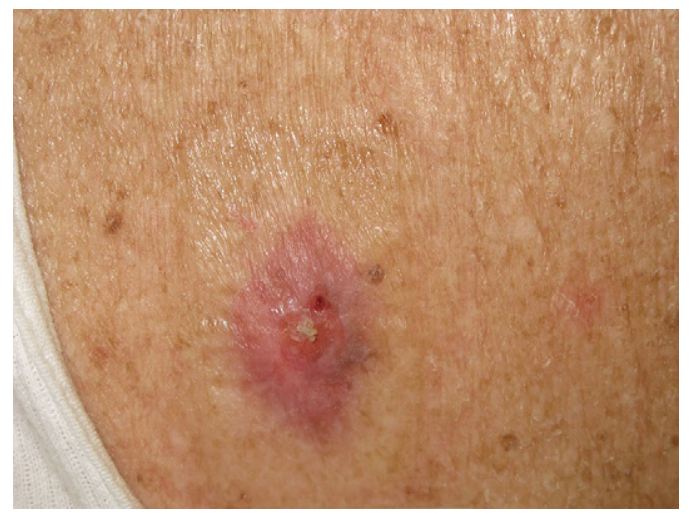

Fig.13. A desmoplastic melanoma. The lesion is a pink, erythematous, ill-defined plaque that has a central ulcer. These lesions are frequently misdiagnosed clinically as superficial basal cell carcinomas.

prognostic indicator, ${ }^{67}$ likely due to the related aggressiveness of the tumor or delayed diagnosis of the lesion. Other factors implicated in the prognosis of melanoma include melanoma invasion of lymphatics, angioinvasion, perineural invasion, melanoma nest satellites distal to the primary tumor, elevated lactate dehydrogenase levels, anatomic location (head and neck lesions with worse prognosis), and increased mitotic rate.

The diagnosis of melanoma can be difficult and more recently, molecular diagnostic methods, such as using comparative genomic hybridization, have allowed the measurement of copy number gene aberrations in tumors. It was discovered that over $95 \%$ of melanomas have chromosomal abnormalities whereas the majority of benign nevi do not. ${ }^{68}$ Distinct patterns of genetic alterations, both chromosomal aberrations and the frequency of specific gene mutations, suggest that the various subtypes of melanoma arise from separate mechanistic routes in response to different selective influences. ${ }^{69}$ For example, a study looking at the genetic alterations of melanoma found that those melanomas on skin without chronic sun-induced damage had frequent losses of chromosome 10 and frequent mutations in BRAF, whereas melanomas on skin with chronic sun-induced damage had frequent increases in the number of copies of the CCND1 gene and infrequent mutations in BRAF. KIT has also been identified as an oncogene and potential therapeutic target in melanomas of mucosal membranes, acral skin, and skin with chronic sun-induced damage. This finding is of value, as this subset of melanomas infrequently shows mutations in BRAF. ${ }^{70}$ The observation of such chromosomal aberrations in melanoma, and a virtual

\begin{tabular}{|c|c|c|}
\hline Clark Level & Histologic Location of Melanoma Cells & 10-Year Survival \\
\hline Level I & Epidermis & $99 \%$ \\
\hline Level II & Penetrating the papillary dermis & $96 \%$ \\
\hline Level III & Filling the papillary dermis & $90 \%$ \\
\hline Level IV & Extending to the reticular dermis & $67 \%$ \\
\hline Level V & Invasion of the subcutis & $26 \%$ \\
\hline
\end{tabular}


deficiency of abnormalities in benign nevi, leads to the possibility that chromosomal analysis could be used diagnostically in melanocytic lesions that are ambiguous, based on current methods of assessment.

\section{Melanoma Therapy}

Surgical excision is the standard of care for all primary melanomas, and consists of en bloc excision of the tumor or biopsy site with a margin containing normal appearing skin and underlying subcutaneous tissue. For decades, excision margins of $5 \mathrm{~cm}$ or greater in all directions from the tumor border were the standard of care. However, a recent meta-analysis showed no statistically significant difference in overall mortality when comparing wide versus narrow excision margins. Based on the World Health Organization, Australian, and European trials, a 1-cm margin is accepted as adequate for thin melanomas. The recommended maximum margin for melanomas between 1 and $4 \mathrm{~mm}$ is $2 \mathrm{~cm} .{ }^{71}$ Controversy exists around the significance of the early detection and management of microscopically positive lymph nodes detected by sentinel lymph node biopsy. Nonetheless, complete lymphadenectomy is recommended when positive nodes are detected. ${ }^{72}$ Metastatic disease is incurable in most affected people, because melanoma does not respond to most systemic treatments. A recent Cochrane review showed an increased response to treatment when immunotherapy was added to chemotherapy, but no difference was seen in survival rate and toxic effects were increased. ${ }^{73}$

The outcome of melanoma depends on the stage at presentation. LM is by definition a Stage 0 disease; it is a malignancy in situ. LM has not ventured beyond the basement membrane into the dermis where lymphovascular invasion and subsequent metastases become possible. Therefore, it is curable if completely excised. Controversy exists regarding the surgical margins. Despite the general agreement of 5-mm surgical margin, it is shown to be adequate in less than $50 \%$ of cases of LM. ${ }^{74}$ MMS offers intraoperative margin assessment, but its drawback lies in the interpretation of frozen sectioned melanocytic lesions. When surgery is technically difficult or cosmetically undesired, other methods can be employed such as cryotherapy, laser therapy, radiation therapy, and immunotherapy (eg, imiquimod). The challenge is to strike a balance between the risks and benefits of a given therapeutic approach. ${ }^{75}$

\section{OTHER MALIGNANT CUTANEOUS NEOPLASMS Merkel Cell Carcinoma}

Merkel cell carcinoma, otherwise known as primary cutaneous neuroendocrine carcinoma, was initially described as trabecular carcinoma by Toker in $1972 .{ }^{76}$ Merkel cell carcinoma became the official name due to the presence of neuroendocrine granules within the cells, which is a characteristic feature of Merkel cells. ${ }^{77}$

The age-adjusted incidence of Merkel cell carcinoma is 0.24 in 100,000 personyears. The incidence is higher in men than women, and it is considered primarily a disease of older or immunosuppressed Caucasian individuals. The incidence in one study in those 65 to 74 years old was 15 times that of those younger than $65 . .^{78}$ Because the lesion appears most frequently on the head and neck, UV radiation is thought to be a major factor that contributes to its development. Because these lesions may appear on non-sun-exposed areas (though less frequently), genetics is thought to play a role as well. Recently the Merkel cell polyomavirus has been cited as a contributing factor to the development of Merkel cell carcinoma. ${ }^{79}$

The classic presentation of a Merkel cell carcinoma is a single, smooth, violet nodule on solar-damaged skin near the periorbital area with telangiectasias found overlying 
the nodule (Fig. 14). When it begins growing, it starts slowly but then progresses to more rapid growth, which usually portends a poor prognosis. Eleven to fifteen percent of patients have positive nodes on presentation, and $50 \%$ have metastasis to regional lymph nodes. Fifty percent have distant metastasis to distant nodes, liver, bone, brain, lung, and skin. ${ }^{78}$

The tumor is comprised histologically of small, round to oval cells of uniform size, with a vesicular nucleus and multiple small nucleoli (Fig. 15). Mitoses and apoptotic bodies are frequently observed. The tumor can mimic histologically both basal cell carcinoma and small cell carcinomas of the lung. Merkel cell carcinomas characteristically stain positively with CK20 and neuron-specific enolase, differentiating it from other primary tumors of the skin such as basal cell carcinoma. It has recently been reported that tumor depth on histologic evaluation may be a factor in the prognosis of these patients. ${ }^{80}$

Surgery is the mainstay of treatment, with guidelines recommending MMS over conventional surgery, and wide local excision of the primary site with all efforts focused on the achievement of clear surgical margins during initial resection. Guidelines recommend sentinel lymph node biopsy to maximize the detection and care of regional disease. Based on the stage of the disease, adjuvant therapies such as radiotherapy and chemotherapy may be indicated. The addition of postsurgical locoregional radiotherapy tends to decrease local and regional recurrence rates, and to prolong relapse-free survival. However, the role of chemotherapy in the treatment of Merkel cell carcinoma remains controversial. ${ }^{81}$

\section{Microcystic Adnexal Carcinoma}

Microcystic adnexal carcinomas are rare, aggressive tumors that were first documented in 1982. The median age of patients with these carcinomas is 56 years, with approximately equal sex distribution. Microcystic adnexal carcinoma has primarily been documented to affect whites; however, there has been one case reported in a black patient.

Case reports primarily describe a pale yellow nodule or plaque with irregular borders, which may take decades to reach full symptomatic potential. Common areas of distribution include the nasolabial and periorbital areas in the majority, with some

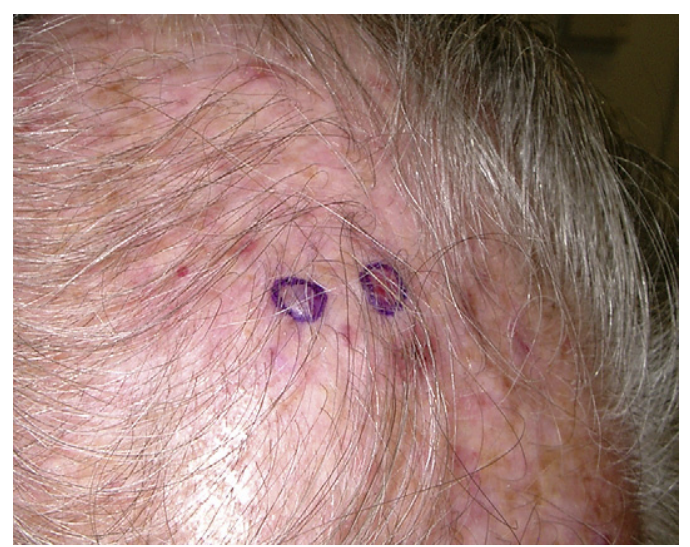

Fig. 14. A Merkel cell carcinoma. On the scalp there are 2 bluish papules that have telangiectasis. The clinician submitted the lesion as a basal cell carcinoma. The biopsy (Fig. 15) proved it to be a Merkel cell carcinoma. 


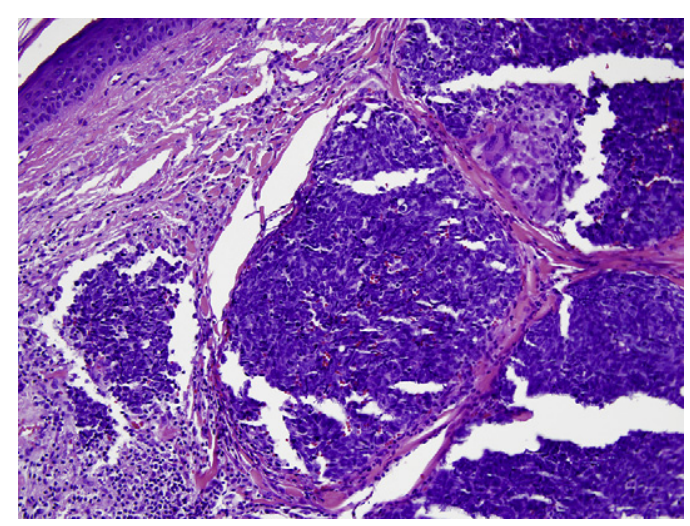

Fig. 15. Histologic image of a Merkel cell carcinoma under light microscopy (original magnification $\times 20$ ). On low magnification these tumors mimic basal cell carcinomas. The tumors do not show clefting or mucin typically seen in basal cell carcinomas. There are round, small, oval cells uniform in size with multiple nucleoli. Mitosis and apoptotic figures are numerous. The cells are present in sheets and nests, infiltrating deep into the dermis. Merkel cell carcinomas show a characteristic perinuclear dot pattern, with CK20 immunoperoxidase staining assisting in the diagnosis.

rare cases demonstrating lesions in the axilla, buttocks, or scalp. The disease is known to be locally aggressive, with cases where it has invaded as deeply as skeletal muscle. There have been only a few cases of metastasis. ${ }^{82-84}$

The lesion originates in the dermis and is poorly circumscribed. Basaloid keratinocytes and ducts are 2 primary components. The keratinocyte component may have horn cysts and premature hair follicles. As the cancer extends through the dermis to deeper layers, the keratinocyte/ductal islands reduce in size. ${ }^{52}$

\section{Mucinous Carcinoma}

Mucinous carcinoma is thought to arise from sweat glands. It is estimated that the annual incidence of mucinous carcinoma is 0.1 per million. ${ }^{85}$ This figure may be underestimated because mucinous carcinoma is often mistaken for a benign tumor.

The tumor clinically presents as a skin-colored to bluish subcutaneous or superficial lesion, most often located in the area of the eyelid. This lesion can be primary or secondary to an underlying malignancy. Internal malignancies of the colon and breast must be ruled out by the clinician, based on clinical, radiologic, and pathologic correlation.

The tumor is composed histopathologically of groups of epithelial cells in the form of ducts, nests, or cords, which are separated by clear areas that contain cells containing mucin. The epithelial cells are strongly positive for periodic acid Schiff and Alcian blue at a $\mathrm{pH}$ of $2.5 .^{52}$

Management includes full workup to exclude the possibility of underlying malignancy, and to determine if the lesion is primary excision with appropriate margins. MMS has been previously used to cure primary lesions. ${ }^{86}$

\section{Aggressive Digital Papillary Adenocarcinoma}

Just as with the other sweat gland carcinomas mentioned (microcystic adnexal carcinoma and mucinous carcinoma), this is a rare condition. Most cases have been in men 
in their sixth and eighth decades, although there have been a few in individuals younger than 20 years.

On presentation, lesions may be painful and mimic a benign "cyst," pyogenic granuloma, soft tissue infection, or a nonspecific ulcer. Thus, aggressive adenocarcinoma of the digit should be suspected clinically in a patient with a painful tumor of the digit. ${ }^{87}$

This tumor is marked by dermal ductal and tubuloalveolar structures, which have papilla that project into cystlike openings. In addition, these papilla are lined by epithelial cells that project into smaller cystlike structures. Recurrence rates without appropriate excision approach $50 \%$, but surgical reexcision or amputation with negative histologic margins reduce recurrence rates to $5 \% .88$

\section{SUMMARY}

Skin cancers may be derived from any part of the skin, and the classification of all variants is extensive. Overall they are the most common cancers of the body, and include those that are highly mortal and those that are associated with an increased morbidity. In this review the most common skin cancers confronted by the clinician and their management are discussed. New associations are highlighted, as well as new information that can help the clinician to better understand the pathogenesis of many of these entities.

\section{REFERENCES}

1. Gloster HM, Brodland DG. The epidemiology of skin cancer. Dermatol Surg 1996; 22:217-26.

2. Miller DL, Weinstock MA. Nonmelanoma skin cancer in the United States: incidence. J Am Acad Dermatol 1994;30:774-8.

3. American Cancer Society, 2008 statistics. Available at: http://www.cancer.org/ downloads/STT/2008CAFFfinalsecured.pdf. Accessed June 10, 2009.

4. Freudenthal W. Verruca senilis und Keratoma senile. Arch Dermatol Syphilol (Berlin) 1926;158:539-44 [in German].

5. Pinkus $\mathrm{H}$. Keratosis senilis: a biologic concept of its pathogenesis and diagnosis based on the study of normal epidermis and 1730 seborrheic and senile keratoses. Am J Clin Pathol 1958;29:193-207.

6. Green A, Beardmore G, Hart V, et al. Skin cancer in a Queensland population. J Am Acad Dermatol 1988;19:1045-52.

7. Marks R, Foley P, Goodman G, et al. Spontaneous remission of solar keratoses: the case for conservative management. Br J Dermatol 1986;155:649-55.

8. Marks R, Rennie G, Selwood TS. Malignant transformation of solar keratoses to squamous cell carcinoma. Lancet 1988;1:795-7.

9. Dodson JM, DeSpain J, Hewett JE, et al. Malignant potential of actinic keratoses and the controversy over treatment. Arch Dermatol 1991;127:1029-31.

10. Chuang TY, Heinreich LA, Shultz MD, et al. PUVA and skin cancer, a historical cohort study on 492 patients. J Am Acad Dermatol 1992;26(2 Pt 1):173-7.

11. Beirn SF, Judge $P$, Urbach F, et al. Skin cancer in County Galway, Ireland. Proc Natl Cancer Conf 1970;6:489-500.

12. Schwartz RA. Premalignant keratinocytic neoplasms. J Am Acad Dermatol 1996; 35:223-42.

13. Boyd AS, Stasko T, Cameron GS, et al. Histologic features of actinic keratosis in solid organ transplant recipients and healthy controls. J Am Acad Dermatol 2001; 45:217-21. 
14. Guba M, Graeb C, Jauch KW, et al. Pro- and anti-cancer effects of immunosuppressive agents used in organ transplantation. Transplantation 2004;77:1777-82.

15. Fu W, Cockerell C. The actinic (solar) keratosis: a 21st-century perspective. Arch Dermatol 2003;139:66-70.

16. Mclntyre WJ, Downs M, Bedwell SA. Treatment options for actinic keratosis. Am Fam Physician 2007;76(5):667-71.

17. Vatve M, Ortonne JP, Birch-Machin MA, et al. Management of field change in actinic keratosis. Br J Dermatol 2007;157(Suppl 2):21-4.

18. Hutchinson JA. Morbid growths and tumours: the crateriform ulcer of the face, a form of acute epithelial cancer. Trans Pathol Soc Lond 1889;40:275-81.

19. Rudolph R, Gray AP, Leipold HW. Intracutaneous cornifying epithelioma ("keratoacanthoma") of dogs and keratoacanthoma of man. Cornell Vet 1977;67:254-64.

20. Griffiths RW. Keratoacanthoma observed. Br J Plast Surg 2004;57:485-501.

21. Schwartz RA. Keratoacanthoma: a clinico-pathologic enigma. Dermatol Surg 2004;30:326-33.

22. Buescher L, DeSpain JD, Diaz-Arias AA, et al. Keratoacanthoma arising in an organoid nevus during childhood: case report and literature review. Pediatr Dermatol 1991;8:117-9.

23. Oh CK, Son HS, Lee JB, et al. Intralesional interferon alfa-2b treatment of keratoacanthomas. J Am Acad Dermatol 2004;51:S177-80.

24. Kwittken J. A histologic chronology of the clinical course of the keratocarcinoma (so called keratoacanthoma). Mt Sinai J Med 1975;42:127-35.

25. Seifert A, Nasemann T. Keratoacanthoma and its clinical variants. Review of the literature and histopathologic analysis of 90 cases. Hautarzt 1989;40:189-202.

26. Beham A, Regauer S, Soyer HP, et al. Keratoacanthoma: a clinically distinct variant of well differentiated squamous cell carcinoma. Adv Anat Pathol 1998;5: 269-80.

27. Batinac T, Zamolo G, Coklo M, et al. Possible key role of granzyme B in keratoacanthoma regression. Med Hypotheses 2006;66:1129-32.

28. Gottfarstein-Maruani $A$, Michenet $P$, Kerdraon $R$, et al. Keratoacanthoma: two cases with intravascular spread. Ann Pathol 2003;23:438-42.

29. Drake AL, Walling HW. Variations in presentation of squamous cell carcinoma in situ (Bowen's disease) in immunocompromised patients. J Am Acad Dermatol 2008;59(1):68-71.

30. Kao GF. Carcinoma arising in Bowen's disease. Arch Dermatol 1986;122:1124.

31. Graham JH, Helwig EB. Bowen's disease and its relationship to systemic cancer. Arch Dermatol 1959;80:133.

32. Lee MM, Wick MM. Bowen's disease. Clin Dermatol 1993;11:43-6.

33. Patel GK, Goodwin R, Chawla M, et al. Imiquimod 5\% cream monotherapy for cutaneous squamous cell carcinoma in situ (Bowen's disease): a randomised, double-blind, placebo-controlled trial. J Am Acad Dermatol 2006;54:1025-32.

34. Cox NH, Eedy DJ, Morton CA, et al. British Association of Dermatologists. Guidelines for management of Bowen's disease: 2006 update. $\mathrm{Br} J$ Dermatol 2007; 156(1):11-21.

35. Karagas MR, Stannard VA, Mott LA, et al. Use of tanning devices and risk of basal cell and squamous cell skin cancers. J Natl Cancer Inst 2002;94(3):224-6.

36. Kasiske BL, Snyder JJ, Gilbertson DT, et al. Cancer after kidney transplantation in the United States. Am J Transplant 2004;4:905-13.

37. Ramsay HM, Reece SM, Fryere AA, et al. Seven-year prospective study of nonmelanoma skin cancer incidence in UK renal transplant recipients. Transplantation 2007;84:437-9. 
38. Bordea C, Wojnarowska F, Millard PR, et al. Skin cancers in renal-transplant recipients occur more frequently than previously recognized in a temperate climate. Transplantation 2004;77:574-9.

39. Cassarino DS, Derienzo DP, Barr RJ. Cutaneous squamous cell carcinoma: a comprehensive clinicopathologic classification-part two. J Cutan Pathol 2006;33(4):261-79.

40. Crouch HE. History of basal cell carcinoma and its treatment. J R Soc Med 1983; 76(4):302-6.

41. Nouri K, Romanelli P, Trent J, et al. Rare presentation of basal cell carcinoma. J Cutan Med Surg 2002;6(3):226-8.

42. Kricker A, Armstrong B, English D, et al. A case-control study of non-melanocytic skin cancer and sun exposure in Western Australia. J Cancer Res Clin Oncol 1991;117(Suppl II):S75.

43. Kricker A, Armstrong BK, English DR, et al. Does intermittent sun exposure cause basal cell carcinoma? a case-control study in Western Australia. Int J Cancer 1995;60:489-94.

44. De Gruijl FR, Sterenborg HJ, Forbes PD, et al. Wavelength dependence of skin cancer induction by ultraviolet irradiation of albino hairless mice. Cancer Res 1993;52:1-8.

45. Scotto J, Fears TR, Fraumeni JF. Incidence of nonmelanoma skin cancer in the United States. Washington, DC: US Department of Health and Human Services; 1983.

46. Gandini S, Raimondi S, Gnagnarella P, et al. Vitamin D and skin cancer: a metaanalysis. Eur J Cancer 2009;45(4):634-41 [Epub 2008 Nov 12].

47. Kleydman Y, Manolidis S, Ratner D. Basal cell cancer with intracranial invasion. J Am Acad Dermatol 2009;60(6):1045-9.

48. Elghissassi I, Mikou A, Inrhaoun $\mathrm{H}$, et al. Metastatic basal cell carcinoma to the bone and bone marrow. Int J Dermatol 2009;48(5):481-3.

49. Elder D, Elenitsas R, Johnson B Jr, et al, editors. Lever's histopathology of the skin. 9th edition. Philadelphia: Lippincott Williams and Wilkins; 2005. p. 715-1157.

50. Kraemer KH, Lee MM, Scotto J. Xeroderma pigmentosum: cutaneous, ocular, and neurologic abnormalities in 830 published cases. Arch Dermatol 1987;123: 241-50.

51. Xie J, Murone M, Luoh SM, et al. Activating smoothened mutations in sporadic basal-cell carcinoma. Nature 1998;391:90-2.

52. Neville JA, Welch E, Leffell DJ. Management of nonmelanoma skin cancer in 2007. Nat Clin Pract Oncol 2007;4(8):462-9.

53. Nguyen T, Ho D. Nonmelanoma skin cancer. Curr Treat Options Oncol 2002;3: 193-203.

54. Available at: http://www.fda.gov/cder/foi/label/2004/20723s016lbl.pdf. Accessed August 1, 2009.

55. Rhodes LE. Photodynamic therapy using topical methyl aminolevulinate vs. surgery for nodular basal cell carcinoma. Arch Dermatol 2004;4:17-23.

56. Kovach BT, Murphy G, Otley CC, et al. Oral retinoids for chemoprevention of skin cancers in organ transplant recipients: results of a survey. Transplant Proc 2006; 38(5):1366-8.

57. Beral V, Evans $\mathrm{S}$, Shaw $\mathrm{H}$, et al. Cutaneous factors related to the risk of malignant melanoma. Br J Dermatol 1983;109(2):165-72.

58. Pfahlberg A, Kölmel KF, Gefeller O, Febim Study Group. Timing of excessive ultraviolet radiation and melanoma: epidemiology does not support the existence 
of a critical period of high susceptibility to solar ultraviolet radiation-induced melanoma. Br J Dermatol 2001;144(3):471-5.

59. Clough-Gorr KM, Titus-Ernstoff L, Perry AE, et al. Exposure to sunlamps, tanning beds, and melanoma risk. Cancer Causes Control 2008;19(7):659-69.

60. Ting W, Schultz K, Cac NN, et al. Tanning bed exposure increases the risk of malignant melanoma. Int J Dermatol 2007;46(12):1253-7.

61. Giuliano AE, Cochran AJ, Morton DL. Melanoma from unknown primary site and amelanotic melanoma. Semin Oncol 1982;9(4):442-7.

62. Ackerman AB. Malignant melanoma. A unifying concept. Am J Dermatopathol 1980;2(4):309-13.

63. Ludgate MW, Fullen DR, Lee J, et al. The atypical Spitz tumor of uncertain biologic potential: a series of 67 patients from a single institution. Cancer 2009; 115(3):631-41.

64. Tran KT, Wright NA, Cockerell CJ. Biopsy of the pigmented lesion-when and how. J Am Acad Dermatol 2008;59(5):852-71.

65. Clark WH Jr, From L, Bernardino EA, et al. The histogenesis and biologic behavior of primary human malignant melanomas of the skin. Cancer Res 1969;29(3): 705-27.

66. Balch CM, Buzaid AC, Soong SJ, et al. Final version of the American Joint Committee on Cancer staging system for cutaneous melanoma. J Clin Oncol 2001;19(16):3635-48.

67. Balch CM, Wilkerson JA, Murad TM, et al. The prognostic significance of ulceration of cutaneous melanoma. Cancer 1980;45(12):3012-7.

68. Bastian BC. Molecular genetics of melanocytic neoplasia: practical applications for diagnosis. Pathology 2004;36(5):458-61.

69. Curtin JA, Fridlyand J, Kageshita T, et al. Distinct sets of genetic alterations in melanoma. N Engl J Med 2005;353(20):2135-47.

70. Curtin JA, Busam K, Pinkel D, et al. Somatic activation of KIT in distinct subtypes of melanoma. J Clin Oncol 2006;24(26):4340-6.

71. Lens MB, Nathan P, Bataille V. Excision margins for primary cutaneous melanoma: updated pooled analysis of randomized controlled trials. Arch Surg 2007; 142(9):885-91.

72. Easson AM, Rotstein LE, McCready DR. Lymph node assessment in melanoma. J Surg Oncol 2009;99:176-85.

73. Sasse AD, Sasse EC, Clark LGO, et al. Chemoimmunotherapy versus chemotherapy for metastatic malignant melanoma. Cochrane Database Syst Rev 2007;(1):CD005413. DOI:10.1002/14651858.CD005413.pub2.

74. Agarwal-Antal N, Bowen GM, Gerwels JW. Histologic evaluation of lentigo maligna with permanent sections: implications regarding current guidelines. J Am Acad Dermatol 2002;47:743-8.

75. Smalberger GJ, Siegel DM, Khachemoune A. Lentigo maligna. Dermatol Ther 2008;21(6):439-46.

76. Toker C. Trabecular carcinoma of the skin. Arch Dermatol 1972;105:107-10.

77. Tang CK, Toker C. Trabecular carcinoma of the skin: an ultrastructural study. Cancer 1978;42:2311-21.

78. Agelli C, Clegg LX. Epidemiology of primary Merkel cell carcinoma in the United States. J Am Acad Dermatol 2003;49:832-41.

79. Feng $H$, Shuda $M$, Chang $Y$, et al. Clonal integration of a polyomavirus in human Merkel cell carcinoma. Science 2008;319(5866):1096-100.

80. Andea AA, Coit DG, Amin B, et al. Merkel cell carcinoma: histologic features and prognosis. Cancer 2008;113(9):2549-58. 
81. Henness S, Vereecken P. Management of Merkel tumours: an evidence-based review. Curr Opin Oncol 2008;20(3):280-6.

82. Yugueros P, Kane WJ, Goellner JR. Sweat gland carcinoma: a clinicopathologic analysis of an expanded series in a single institution. Plast Reconstr Surg 1998;102(3):705-10.

83. Ohta $M$, Hiramoto $M$, Ohtsuka $H$. Metastatic microcystic adnexal carcinoma: an autopsy case. Dermatol Surg 2004;30(6):957-60.

84. Gabillot-Carre M, Weill F, Mamelle G, et al. Microcystic adnexal carcinoma: report of seven cases including one with lung metastasis. Dermatology 2006;212(3): 221-8.

85. Breiting L, Christensen L, Dahlstrøm K, et al. Primary mucinous carcinoma of the skin: a population-based study. Int J Dermatol 2008;47(3):242-5.

86. Marra DE, Schanbacher CF, Torres A. Mohs micrographic surgery of primary cutaneous mucinous carcinoma using immunohistochemistry for margin control. Dermatol Surg 2004;30(5):799-802.

87. Frey J, Shimek C, Woodmansee C, et al. Aggressive digital papillary adenocarcinoma: a report of two diseases and review of the literature. J Am Acad Dermatol 2009;60(2):331-9.

88. Duke WH, Sherrod TT, Lupton GP. Papillary adenocarcinoma (aggressive digital papillary carcinoma revisited). Am J Surg Pathol 2000;24:775-84. 